\title{
《教育培训学科》修订版 (ISCED-F)
}

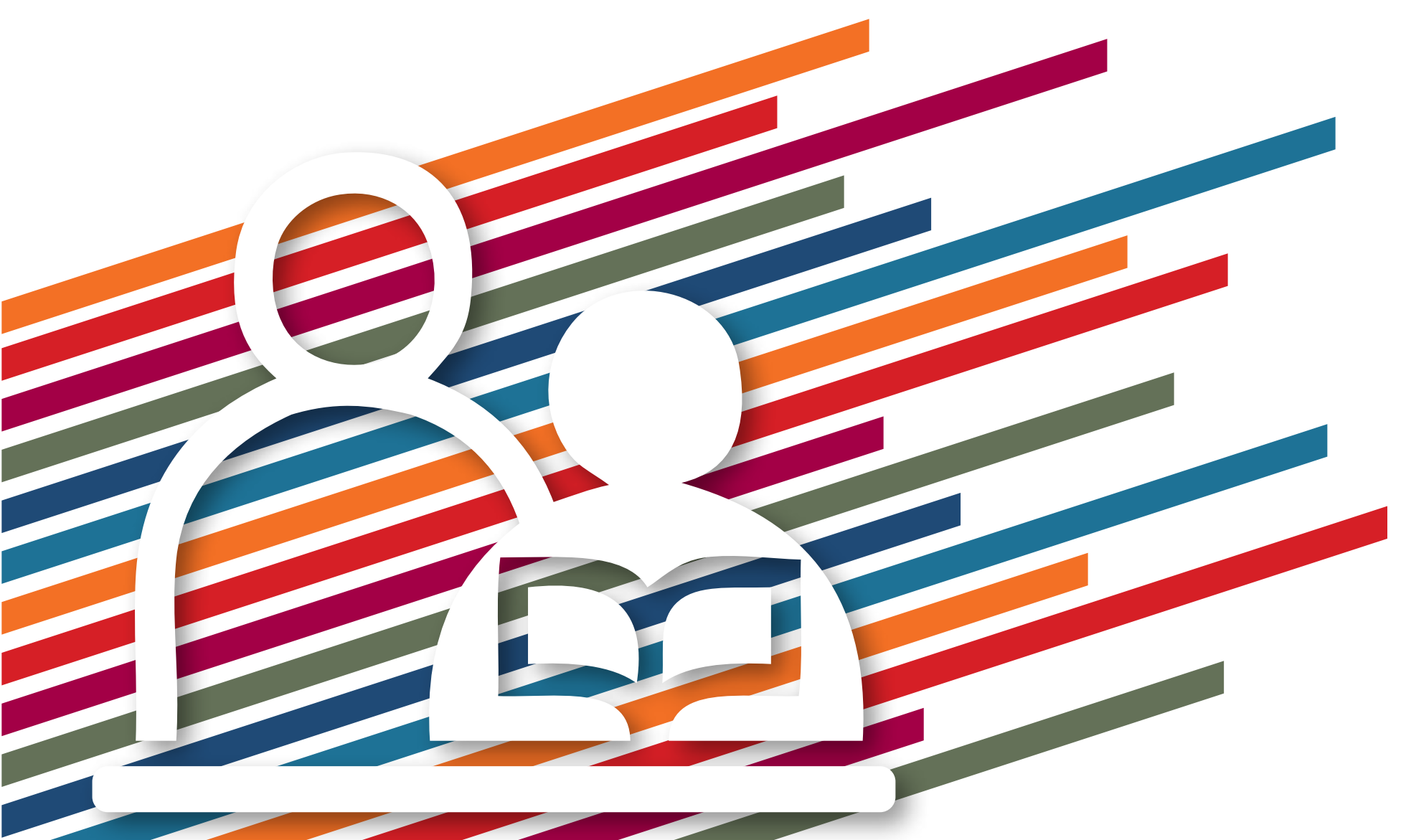




\section{联合国教科文组织 (UNESCO)}

联合国教科文组织 (UNESCO) 宪章在 1945 年 11 月召开的伦敦大会上由 20 个国家通过, 并于 1946 年 11 月 4 日生效。联合国教科文组织目前有 195 个成员国和 9 个准会员。

联合国教科文组织的主要宗旨是致力于世界的和平与安定。它通过推动成员国在教育、科技、文 化和信息领域的合作, 促进对联合国宪章确认的无论种族、性别、语言和宗教, 人人均应享有的 正义、法治、人权和基本自由的普遍尊重。

为实现此目标, 联合国教科文组织履行以下五项主要职能：1）关于明日世界在教育、科技、文化 和信息前瞻性研究；2）通过研究、培训和教育活动推进、传播和分享知识；3）制定活动标准, 起草和采用内部工具和法规建议标准；4）通过技术合作专长，支持成员国的发展政策和项目；5） 交流信息。

联合国教科文组织总部设在法国巴黎

\section{联合国教科文组织统计研究所 (UIS)}

联合国教科文组织统计研究所是联合国教科文组织的统计机构，是教育、科技、文化和信息方面 国际统计资料的保管者。

联合国教科文组织统计研究所成立于 1999 年。其成立的目的在于改善联合国教科文组织的统计项 目, 编制和发布及时、准确且与政策相关的统计资料, 以应对当今日益复杂多变的社会、政治和 经济环境的需求。

联合国教科文组织统计研究所位于加拿大蒙特利尔。

联合国教科文组织统计研究所

2014 年出版

地址: P.O. Box 6128, Succursale Centre-Ville

Montreal, Quebec H3C 3J7

Canada

电话: (1 514) 343-6880

邮箱: uis.publications@unesco.org

网站: http://www.uis.unesco.org

OUNESCO-UIS 2014

ISBN 978-92-9189-160-3

Ref: UIS/2014/INS/4

DOI http://dx.doi.org/10.15220/978-92-9189-160-3-ch

此书/期刊为开放获取出版物, 授权为 Attribution-NonCommercial-ShareAlike 3.0 IGO (CC-BY-NC-SA 3.0 IGO) (http://creativecommons.org/licenses/by-nc-sa/3.0/igo/)。此出版物内容的使用者无条件接受遵守教科文组织开放获取储 存档的一切条件和规则 (www.unesco.org/open-access/terms-use-ccbyncsa-chi)。

本出版物所用名称及其材料的编制方式并不意味着联合国教科文组织对于任何国家、领土、城市、地区或其当局的法律 地位，或对于其边界或界线的划分，表示任何意见。 


\section{内容}

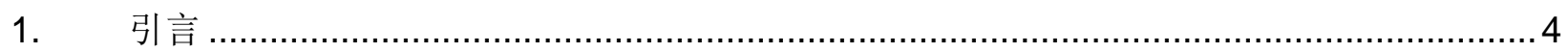

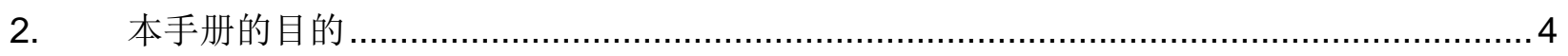

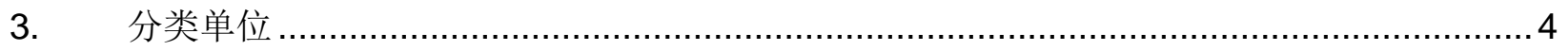

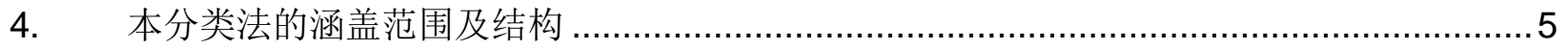

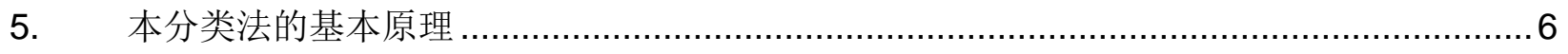

6. 分类准则的应用: 一些例子 ………………………………………………………....

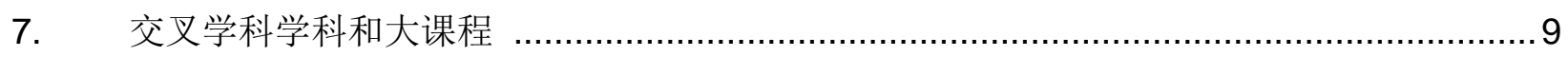

8. 其它困难情形的编码 …………………………………………………………………. 10

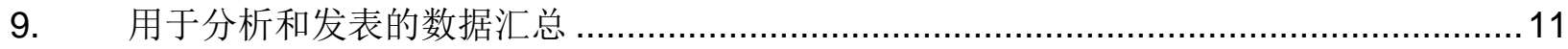

10. 与《国际教育标准分类法》2 2011 版及其它分类法的关系 ………………………………....11

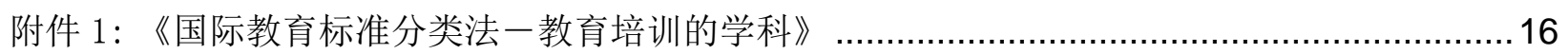




\section{1. 引言}

1. 《国际教育标准分类法》是一个收集、汇编和分析国家间可比较教育统计的框架。《国际教 育标准分类法》是《联合国经济与社会分类法国际系列》中的一员, 是一个以教育等级和学 科来组织安排教育课程和相关资格证书的参考分类。 《国际教育标准分类法》最先由联合国 教科文组织（UNESCO）于 20 世纪 70 年代中期开发, 并经过两次修订一一最近是在 2011 年。 《国际教育标准分类法》是国际协议的产物，并经联合国教科文组织成员国大会正式通过。

2. 最新修订的《国际教育标准分类法》2011 版, 主要着重于对课程的教育等级 ( ISCED-P) 的 修改，并首次引入一个以资格证书为基础的的受教育程度等级分类法（ISCED-A）。

3. 《国际教育标准分类法》 2011 修订版的复审过程中决定, 应该建立一个独立但与之相关的分 类法, 单独对教育的学科进行检查, 并且合适的话, 能以与教育和受教育程度等级的未来修 订不同的频率进行更新。等级与学科的分类将作为同一分类法家族中的一部分加以保留。据 此，这个新的分类法将被称为《国际教育标准分类法一教育培训的学科》（ISCED-F）。

\section{2. 本手册的目的}

4. 拥有一部共同的国际分类法, 仅是向收集可比较数据迈出了第一步。第二步是保证该分类法 在各国家应用的一致性。因此, 本手册的目的是给如何应用《国际教育标准分类法一教育培 训的学科》提供一个明确的指导方针, 详细规定一些要遵守的标准, 提供每个教育培训学科 的包含和排除列表。附件 1 详细描述了《国际教育标准分类法一教育培训的学科》的分类。 本分类法将附有一个综合列表, 给出每一学科的定义以及各学科包含和排除课目的例子, 以 帮助国家区分每一学科间的界限。为便于参考, 综合列表将给出一个字母顺序表和数字顺序 表。

\section{3. 分类单位}

5. 《国际教育标准分类法》2011 版的基本分类单位是教育课程及其相关的资格证书。在《国际 教育标准分类法一教育培训的学科》 ( ISCED-F) 中, 也同样是这些分类单位。

a. 教育课程系指 “一套连贯或序列的教育活动, 为在一段持续的时期内达到预定的学习目 标或完成一组具体的教育任务而设计和组织的”。教育活动是有意识的活动, 涉及旨在 引起学习的某种交流形式。

b. 资格证书是，“正式确认，通常采用文件的形式，证明成功完成一个教育课程或课程的 某个阶段。因成功完成单独的课（例如单元或课目）而授予的学分在《国际教育标准分 类法》中不视为资格证书。在这种情况下, 持续时间等同于一个完整课程或涵盖一个完 整课程的全部课目的足够学分或课目才可以代表一个资格证书”。 
6. 《国际教育标准分类法一教育培训的学科》 ( ISCED-F), 根据学习的学科, 划分教育课程及 相关的资格证书。

\section{a. 学科是 “一个教育课程 或资格证书所涵盖的内容的门类、分支或领域”。}

7. 教育培训的学科和教育等级或受教育程度等级是《国际教育标准分类法》中交叉学科分类变 量, 因此它们相互独立。特别是, 与《国际教育标准分类法》原始版 (《国际教育标准分类 法》1976 版) 不同, 学科不在教育等级中界定。因为课程和资格证书仅见于某些教育培训 学科, 某些教育等级中因国家或时间变化而不同。例如, 不同的国家在不同的教育等级中, 提供教师培训或护理。近年, 形成了一种倾向, 在低一些的教育等级中逐步淘汰这些课程, 将培训升级到较高的国际标准教育分类法等级中。

\section{4. 本分类法的涵盖范围和结构}

8. 本分类法主旨在描述和归类《国际教育标准分类法》 2011 版中的中等, 中等后和高等正规教 育等级中的教育培训学科, 虽然也可用于分类其它等级中的课程和资格证书。本分类法还可 用于其它情况, 例如对非正规教育, 初始和成人职业培训或非正式学习的课目实质内容进行 分类。

9. 目前本修订以分类法的早期版本为基础, 以尽可能保证跨时间上的可比性。本分类法设计为 3 -级等级体系, 包含宽学科 (最高级), 窄学科 (第 2 级), 细学科 (第 3 级), 并采用 4数字编码体系。教育培训有 11 个宽学科, 29 个窄学科和约 80 个细学科。

\begin{tabular}{llc} 
等级 & 学科类别 & 学科数 \\
\hline 第 1 级 & 宽学科 & 11 \\
第 2 级 & 窄学科 & 29 \\
第 3 级 & 细学科 & $\cong 80$ \\
\hline
\end{tabular}

10. 细学科 (分类第 3 级) 主要用于高等教育, 以及中等和中等后非高等的职业教育和培训课程 及资格证书。本分类法也可用于具有课目专业的普通教育课程和资格证书。但是, 涵盖大范 围课目并在特定的学科或学科系中没有或有很少专业的普通教育课程和资格证书, 分类在宽 学科 00 “通用课程和资格证书”。

11. 虽然开发本分类法的主要目的是用于汇编国家间可比较的教育统计数据, 但是它也适用于国 家层面, 特别是那些还未开发出本国教育学科国家标准分类法的国家。那些希望采纳本分类 法作为本国之用的国家, 可能需要适应或调整学科的某些组别, 以便更好反映该国可学习的 学科的存在和 / 或范围, 并满足国家报告这种类型教育数据的需要。国家的调整不应使得根 据《国际教育标准分类法一教育培训的学科》进行国际报告变得困难或不可能。《国际教育 标准分类法一教育培训的学科》分类法的首要目的就是至少在宽学科级别促进国际间报告。 


\section{5. 本分类法的基本原理}

12. 教育培训学科的分类法遵循课目实质内容的方法。这是以前《国际教育标准分类法》版本 (1976，1997 和 2011) 采用的同样方法。根据课目的类似性, 将内容紧密关联的课目组合在 一起, 形成宽, 窄, 细学科分类。目的是在课程的实质内容而不是所针对的参加者的特征基 础上，根据教育培训的学科将教育课程及相关资格证书分类。

13. 如何决定将一个课程或资格证书划分入教育培训的学科取决于主要的课目实质内容。课目内 容是在课程中传授并被相关的资格证书所认可的实际的、实用的和理论的知识。这种知识应 用于特别类型的问题或特定目的, 可以是抽象的（例如哲学）、实用的（例如工程）或两种 都是（例如建筑）。为了实用，一个课程或资格证书的主要课目由这些细学科占大部分（50\% 以上）学习学分或学生预期学习时间来决定。如果可行, 应该采用学习学分。否则, 应该对 预期学习时间进行一个大致评估。学习时间包括讲课和讲座, 也包括实验或特别的课题。不 包括私自学习时间（因为测定困难和学生差别）。课程和资格证书分类在含有它们主要课目 的细学科中。

14. 如果没有足够的信息决定学习学分或预期学习时间的相对份额, 那么该课程或资格证书应该 分类在其标题第一个所列的学科中。如果由于课程或资格证书包括几个细学科（和，甚至， 窄或宽学科), 其中没一个占主导地位, 导致不能识别主要课目, 那么该课程或资格证书应 该分类在交叉学科类别中。（详细见第 7 节)

15. 如果学习的主要课目是同一的或足够相似, 则两个课程或资格证书属于同一个学科。为了将 教育培训学科分类为宽、窄和细学科, 开发分类法的结构时, 采用下列优先顺序准则确定课 目实质内容的相似程度:

a. 理论知识内容 (如, 所涉及到的想法和概念以及它们在解释事实和预测结果方面的应 用）。

b. 学习目的（如, 所获得的知识、技艺和能力的预期使用）。

c. 兴趣的目标 (如, 所学习的现象、问题或实体)。

d. 方法和技术（如, 学习和应用所获得的技艺和知识的程序）。

e. 工具和设备 (如, 个人学会使用或操作的仪器和器具) 。

16. 理想状况是, 本分类法对国际上宽学科之间保持大体平衡, 就是说全世界作为一个整体没有 一个占主导地位的单个宽学科。例如, 当统计一个课程的注册或毕业生人数时, 不应出现不 成比例的注册 / 毕业生人数集中在一个宽学科而不是另一个。然而, 考虑到国家间教育体系 和教育等级间的巨大差别, 不可能开发出一个单一的分类法对每一个国家或每一个教育等级 都是平衡的。 


\section{6. 分类准则的应用：一些例子}

17. 本分类法中宽和窄学科类别, 与前次《国际教育标准分类法》 1997 修订版中定义的类别相似。 它们主要取决于理论知识的相似度和学习的目的和, 在较小程度上, 所涵盖学科组的兴趣目 标。细学科主要根据方法和技术以及工具和设备来区分。本节余下部分描述这些准则应用的 一些例子，模棱两可情况和两个例外：职业课程和资格证书以及教师培训。

\section{教育等级间的课目内容相似度}

18. 所有教育课程和资格证书都与理论理解、实际知识和实用技术的某种融合有关。不同教育等 级的两个学科, 如果覆盖相似类型的理论、实际和实用知识或技能, 即使相对侧重点不一样, 也属于相同的教育培训学科。例如, 工具制造课程包括一些用于机械工程的数学、实际知识 和工程理论。因此, 工具制造和机械工程应该属于相同的教育培训学科 (0715 “力学与金属 专业“），尽管它们隶属于不同的教育等级或受教育程度。

\section{教育等级中的课目内容相似度}

19. 相比之下, “护理助产” 分类为 0913, 医学为 0912。尽管它们紧密相关, 但是课目实质内容 不同, 特别是学习目的不同 (医生和护士期望获得和应用不同的知识、技艺和能力), 方法 和技术不同, 以及工具和设备不同。采用本分类法的数据用户, 也强烈要求能区分护士和医 生。在某些国家, 医生和护士在同一教育等级学习和获得资格证书。在这些事例中, 更容易 通过学科而不是教育等级来区分它们。

\section{模棱两可情况}

20. 当一个课程或资格证书与分类中的两个学科紧密相关时, 就会出现模棱两可情况。例如, 兽 医学习与医学 (特别是理论知识以及学习目的) 和畜牧学 (兴趣目标、方法和技术、以及工 具和设备) 都有相似性。选用后者分类兽医学习, 以保证与《国际教育标准分类法》以前版 本相关关键分类法 (如, 科学学科以及《所有经济活动的国际标准工业分类法》 (ISIC) )

一致，并为（人类）卫生和福利保留一个宽学科，以利于国家政策分析。

21. 另一个例子是护理。医疗护理分类在窄学科 091 “卫生” , 非医疗护理在 092 “福利” , 因为 这两个学科所要求的理论知识非常不同。

\section{通用课程}

22. 通用课程包括语言和文学、社会和自然科学、数学、艺术和 / 或体育等一系列课目, 应分类 在 0011 “基础课程和资格证书” 。即使出现在一定类别课目内容如人文科学、社会科学、自 然科学等方面有所侧重, 也应归于本类情形。这些课程是特定类型的交叉学科或宽课程, 为 其设有一个宽学科。因此, 它们不应该作为交叉学科或宽课程被分类在其它宽学科。 


\section{工程师课程和资格证书}

23. 工程师教育课程和资格证书应包括在细学科 071 “工程 ${ }^{1}$ 与工程行业” 或, 土木或建筑工程教 育课程和资格证书应包括在 0732 “建筑与土木工程” 。即使这些学习是为计算机运算、媒体 技术、纺织、粮食等设立, 只要其重点是设计和制造机器、引擎、电子设备、电器、计算机、 通信等（071）或建筑物、道路和桥梁（0732），它们应被分类在 071 或 0732 。

\section{制造课程}

24. 重点放在工程, 如金属、机械、机器、引擎、电气设备等制造课程, 应该归类于细学科 071 “工程与工程行业”。

25. 其它的制造课程和资格证书应归类于 072 “制造与加工”。侧重制造特定产品如粮食、纺织 品、鞋子、纸张、家具、玻璃、塑料等属于这种情形。但是, 金属产品的制造不包括在窄学 科 072 , 而是包括在细学科 0715 “机械与金属行业”。

\section{语言}

26. 语言应该根据有意参加者 ${ }^{2}$ (在这种特殊情形中, 这代替学习的课目实质内容) 的特征, 归类 于细学科 0231 “语言学习” 或细学科 0232 “文学与语言学”。针对现有母语或流利使用者的 语言课程和资格证书与想掌握该语言的其它语种使用者的语言课程和资格证书，在理论内容、 学习目的和教学风格上, 有明显的差异。前一种情形, 重点在语言的文学和语言学而不是语 法和词汇（至少在中等和高等教育阶段是如此）。在后一种情形, 注重语法和词汇, 也许涉 及文化, 而较少注重文学和语言学。

\section{包含副科的职业课程和资格证书}

27. 在职业课程中, 例如, 有些高级中等教育中的长线课程, 用于副科的总时间多于用于预期职 业的课目实质内容或职业群的时间。尽管如此, 这样的课程及其资格证书应该归类于与预期 职业或职业群有关的职业学科。这是对按照主要或优势课目分类规则的一个例外, 因为它对 于独自区分职业课程和资格证书的目标职业很重要。在实际中, 目标职业的学科, 可能是花 费预期学习时间最多的学科。

例子 1：护理保健课程应该归类于细学科 0913 “护理与助产”, 即使花在其它课目的时间比 护理上更多。

\section{课目材料专业化的教师培训课程和资格证书}

28. 主要致力于讲授课目内容专业的教师培训课程和资格证书, 应该归类于教师培训, 即使其主 要内容是专业化的课目内容。同样的原则应用于将教育或教师培训与专业课目结合起来的课 程和资格证书。这是对按照主要或优势课目规则分类课程和资格证书的一个例外, 特别是在 教育系统分析中，独自将教师培训从其它细学科区分开来很重要。

1 注意, 工程学是一个比工程师更广的概念, 工程师作为一种职业在工程界中工作, 但也有许多其它类别 也在这个领域工作。就教育等级而言, 细学科 071 和 072 没有刻意的区别。

2 如, 学习者是否已经熟悉将要学习的语言。 


\section{7. 交叉学科或宽泛课程和资格证书}

29. 交叉学科或宽课程和资格证书是那些将几个教育和培训的细学科结合在一起并无单个细学科 占主导地位的课程和资格证书。许多交叉学科课程和资格证书涵盖几个窄或甚至宽学科。在 本分类法中, 采用 “主导课目规则” 决定交叉学科学习应被归入的宽学科。即, 主导课目或 几个课目决定 (宽) 学科。决定主导课目的准则, 如前述, 是学习学分或学生预期学习时间 的所占份额。交叉学科课程应在主导宽学科中的窄和细学科层面采用 “ 8 ”, 划为 “涉及 [宽 学科]的交叉学科课程或资格证书”（如, xx88)。这样, 所有无主导课目的交叉学科学习 将分开识别, 并且至少知道该课程或资格证书的主导宽学科。

例子 2: 一个课程包括相等部分 (每一部分 1/3) , 神学 (0221) 、历史 (0222) 和哲学 (0223)，应分类为 0288 (涉及 “艺术与人文的交叉学科课程和资格证书”) 。如果一个课 程包括 60\%神学、20\%历史和 20\%哲学，那它应该被分类为 0221 , 神学是主导课目。

30. 如果发现一个以上主导宽学科, 交叉学科学习应分类在课程或资格证书标题（课目表或教学 大纲, 如果标题未列出) 第一个列出的宽学科中。如果无足够信息确定主导课目, 则应采用 前述 “第一列出” 规则。

31. 涵盖两个或以上细学科的课程或资格证书应分类在其中占据学习学分或预期学习时间的优势 份额的细学科中。因此, 如果学习学分或预期学习时间的主要部份花在一单个细学科, 该课 程或资格证书应分类在该细学科，而不是交叉学科课程／资格证书。

例子 3: 主修数学副修法语的课程应分类在 0541 “数学”, 因为数学是主要课目。

例子 4: 含有 40\%工程（071）、30\%商业（041）和 30\%语言（023）的课程应被分类为0788 ( “涉及与工程、制造与建筑的交叉学科课程和资格证书”) , 因为没有学科占优势, 但是 07 是主导宽学科。如果工程和商业同等重要, 并且多于语言 (如, 40\%、40\%和 20\%), 那么 这个课程将分类在 0788 或 0488, 取决于课程标题先列工程（071）或先列商业（041）（课 目表或教学大纲，如果标题中未列出）。

例子 5: 含有 40\%历史 (0222)、30\%经济 (0311) 和 30\%政治 (0312) 的课程应分类在 0388 ( “涉及与社会科学、新闻与信息的交叉学科课程和资格证书”) , 因为经济和政治在同一 宽学科。

32. 瞄准一个特定职业学科同时也含有其它学科副科的课程和资格证书不应视为交叉学科课程或 资格证书，而应根据其特定职业学科来分类。

例子 6: 在电气安装课程中, 副科 (语言、数学、自然科学等) 比预期职业课目花费更多的 时间。但是，这个课程应分类在 0713 “电力与能源”，而不是交叉学科课程。

33. 由于本手册建议, 分类交叉学科课程和资格证书时只给一个代码, 因此, 这个 “主导课目规 则” 是唯一可行的解决办法。但是, 那些能够分配 2 个或更多编码 ${ }^{3}$ 的用户, 也能够将交叉学 科课程或资格证书分类在学科的组合中。

3 例如, 如果数据储存在花名册中, 并不需要通过家庭或其它的调查方式收集。《国际教育标准分类法一 教育培训的学科》的任何部分都不使用多重编码。但是, 某些国家出于国家目的可决定使用多重编码。 


\section{8. 其它困难情形的编码}

\section{未进一步定义和未在其它地方分类}

34. 当在给特定数据收集中的课程 / 资格证书编码时, 需要在教育培训的学科分类中处理两种常 见的情况:

a. 关于一个给定课程或资格证书的信息还不如分类法的更高分类等级所知道的多的情形。 这些就是所称的 “未进一步定义” 的情形, 并在窄或细学科分类层级（适当的）层面编 码的最后用一个或多个“0”来表示。

例子 7: 不能获得更多信息的工程中的课程应分类为 0710 “未进一步定义的工程与工程 行业”。这样的情况不应当考虑为交叉学科或宽课程。

例子 8: 不能获得更多信息的服务业的一个课程应分类为 1000 “未进一步定义的服务 业”。

b. 已知并且充分描述的特定细学科, 但在分类法中并未明确规定的情形。这就是 “未在其 它地方分类” 的情形, 在分类法的细学科级别采用 “9” 来表示 (例如, 作为最后一个数 码）。

例子 9: 一个不属于任何其它细学科的信息与通信技术中的新学科课程应分类在 0619 “未 在其它地方分类的信息与通信技术”。

这些 “未进一步定义” 和 “未在其它地方分类” 编码没有包括在分类结构中，但是作为补充 编码，可用于处理那些没有充分描述的数据 ( “未进一步定义”) 或未明确包括在分类结构 的数据（“未在其它地方分类”)。

区分 “ $0 ” 、 “ 8 ”$ 和 “ $9 ”$ 的用法可能是困难的。下表可以帮助:

\begin{tabular}{|l|l|l|l|}
\hline 编码 & 名字 & 用法 & 例子 \\
\hline 0 & 未进一步定义 & $\begin{array}{l}\text { 不多于分类法的更高等级已知的 } \\
\text { 信息 }\end{array}$ & 7 和 8 \\
\hline 8 & 交叉学科课程/资格证书 & 无主导细学科的课程/资格证书 & $\begin{array}{l}2 \text { (第一部分), } \\
4 \text { 和 } 5\end{array}$ \\
\hline 9 & 未在其它地方定义 & $\begin{array}{l}\text { 细学科是已知的但没有在分类法 } \\
\text { 中提供 }\end{array}$ & 9 \\
\hline
\end{tabular}

注意, 有主导细学科 (包含 50\%以上学习学分和时间) 的课程和资格证书分类在那个主导学科 （见例子 $1 、 2$ (第 2 部分）、3 和 6 )。 
35. 在数据收集中, 如果完全不知道学习学科, 可使用 “9999” 编码, 或, 在调查时, 仅在窄或 宽学科级别各自采用 “999”或 “99”。

\section{9. 用于分析和发表的数据汇总}

36. 根据信息需要, 本分类法可用于任何层级的数据收集和传播。目的是赋予足够的灵活性以满 足大部分分析和报告的需要。

37. 出于发表的目的, 经常需要广泛数据汇总。例如, 联合国教科组织文统计研究所 (UIS) 发表 宽学科层面的数据。

38. 分析的目的应该给于适当地考虑。除联合国教科组织文统计研究所目前所用之外, 也可以开 发其它的组别, 特别是为了宣传的目的。

\section{0. 与《国际教育标准分类法》2011 版及其它分类法的关系 《国际教育标准分类法》 2011 版的关系}

定向与学科

39. 定向 (普通或职业教育) 和教育培训的学科是《国际教育标准分类法》中的两个不同的标准, 不应混淆。

40. 在《国际教育标准分类法》2011 版中，职业教育定义为：

使学习者获取某种职业或行业或数种职业或行业特定的知识、技艺和能力的教育课程。 职业教育有基于工作的成分（例如实习，双轨制教育课程）。成功完成这样的课程将得 到由有关国家当局和或劳务市场承认的与劳务市场有关的职业资格证书。

41. 在《国际教育标准分类法》2011 版中，普通教育定义为:

系指为发展学习者的普通知识、技艺和能力以及读写和计算技能而设计的教育课程, 通 常为参加者进入《国际教育标准分类法》同级或更高级教育课程做准备, 并为终身学习 奠定基础。

42. 按照《国际教育标准分类法》2011 版, 分类为普通教育定向下的课程和资格证书, 如果在特 定学习学科没有专业化并且涵盖一系列课目, 则应在 “通用课程和资格证书” 宽学科中分类 为 0011 “基础课程和资格证书”。其它普通教育的课程和资格证书，根据其主要课目实质内 容，划分教育培训的学科。特别是作为例外，高等教育等级的普通或学术教育应该仅分类在 “通用课程和资格证书”宽学科。

例子 10: 《国际教育标准分类法》2011 版 5 级的数学教育课程或资格证书也许在定向上是普 通课程, 但是其细学科却应该是 0541 “数学”。 
《国际教育标准分类法一教育培训的学科》与《国际教育标准分类法-教育的学科》1997 版 (和 2011 版） 的对照关系

43. 根据第 5 节的基本原理, 特别是第 15 段的原则, 《国际教育标准分类法一教育培训的学科》 2013 版（ISCED-F）宽学科之间的窄或细学科进行了一些重新分配。如下列对照表（表 1) 所 示。

44. 主要变化是:

a. 《国际教育标准分类法》 1997 版中的学科 22 “人文” 分成两个窄学科: 022 “人文 (不 包括语言）”和 023 “语言”。

b. 《国际教育标准分类法》1997 版中的大类 3 “社会科学、商业与法律” 分成两个宽学科: 03 “社会科学、新闻与信息” 和 04 “商业、行政与法律”。

c. 通过将《国际教育标准分类法》1997 版中的学科 042 “生命科学” 分解并与学科 062 “农业、林业与渔业” 的部分内容组合在一起, 在宽学科 05 “自然科学、数学与统计” 内产生一个新的窄学科 052 “环境”。

d. 将《国际教育标准分类法》1997 版中的大类 4 “科学” 分成两个宽学科: 05 “自然科学、 数学与统计” 和 06 “信息与通信技术 (ICTs)”。

e. 通过将大类 8 “服务业” 中的学科 85 “环境保护” 转移至新的宽学科 07 “工程、制造与 建筑”, 产生一个新的窄学科 0712 “环境保护技术”。

f. 将《国际教育标准分类法》1997 版中的大类 6 “农业” 重新命名, 产生一个新的宽学科 08 “农业、林业、渔业与兽医” , 并将学科 62 “农业、林业与渔业” 中的一些转移至 新的窄学科 052 “环境” 。

g. 从《国际教育标准分类法》 1997 版中的学科 85 “环境保护” 的余下部分创造新的窄学 科 102 “安全服务”。 


\section{表 1: 《国际教育标准分类法一教育培训的学科》 2013 版与《国际教育标准分类法一教育的学科》 1997 版的对照表}

\begin{tabular}{|c|c|}
\hline 《国际教育标准分类法－教育培训的学科》 2013 版 & 《国际教育标准分类法－教育的学科》1997 版（和 2011 版） \\
\hline 00 通用课程和资格证书 & 0 普通课程 \\
\hline 001 基础课程和资格证书 & 01 基础课程 \\
\hline 002 识字和算术 & 08 识字和算术 \\
\hline 003 个人技能和发展 & 09 个人发展 \\
\hline 01 教育 & 1 教育 \\
\hline 011 教育 & 14 教师培训与教育科学 \\
\hline 02 艺术与人文 & 2 人文与艺术 \\
\hline 021 艺术 & 21 艺术 \\
\hline 022 人文 (不包括语言) & \multirow[t]{2}{*}{22 人文 } \\
\hline 023 语言 & \\
\hline 03 社会科学、新闻与信息 & 3 社会科学、商业与法律（商业和法律除外） \\
\hline 031 社会与行为科学 & 31 社会与行为科学 \\
\hline 032 新闻与信息 & 32 新闻与信息 \\
\hline 04 商业、行政与法律 & 3 社会科学、商业与法律（社会科学除外） \\
\hline 041 商业与行政 & 34 商业与行政 \\
\hline 042 法律 & 38 法律 \\
\hline 05 自然科学、数学与统计 & 4 科学 (计算机科学除外) 加上 62 农业, 林业与渔业中的自然公园与野生动植物 \\
\hline 051 生物及相关科学 & 42 生命科学去除其它相关科学 \\
\hline 052 环境 & $\begin{array}{l}42 \text { 生命科学 (其它相关科学) 的一部分, } 62 \text { 农业、林业与渔业 (自然公 } \\
\text { 园、野生动植物) 的一部份 }\end{array}$ \\
\hline 053 物理科学 & 44 物理科学 \\
\hline 054 数学与统计学 & 46 数学与统计学 \\
\hline 06 信息与通信技术 & 4 科学 (仅计算机科学) \\
\hline 061 信息与通信技术 & 48 计算机科学 \\
\hline 07 工程、制造与建筑 & 5 工程，制造与建设（加 85 环境保护的大部分） \\
\hline 071 工程与工程行业 & 52 工程与工程行业 (加 85 环境保护的大部分) \\
\hline 072 制造与加工 & 54 制造与加工 \\
\hline 073 建筑学与建筑工程 & 58 建筑学与建筑工程 \\
\hline 08 农业、林业、渔业与兽医学 & 6 农业 (自然公园与野生动植物除外) \\
\hline 081 农业 & \multirow[t]{3}{*}{62 农业、林业与渔业（自然公园和野生动植物除外） } \\
\hline 082 林业 & \\
\hline 083 渔业 & \\
\hline 084 兽医学 & 64 兽医学 \\
\hline 09 卫生与福利 & 7 卫生与福利 \\
\hline 091 卫生 & 72 卫生 \\
\hline 092 福利 & 76 社会服务 \\
\hline 10 服务业 & 8 服务业（85 环境保护的大部分除外） \\
\hline 101 个人服务业 & 81 个人服务业 \\
\hline 102 卫生与职业卫生服务 & 85 环境保护的一部分 (社区卫生、劳动保护与安全) \\
\hline 103 安全服务 & 86 安全服务 \\
\hline 104 运输服务 & 84 运输服务 \\
\hline
\end{tabular}




\section{与《欧盟培训学科》1997版 (FoT 1997)和《欧盟教育培训学科》1999版(FoET 1999)的关系}

45. 《欧盟培训学科》1997 版(FoT 1997)和《欧盟教育培训学科》1999 版(FoET 1999)分类法系 由《国际教育标准分类法一教育的学科》 1997 版中的分类法发展而来, 除去在等级体系的第 1 和第 2 级 (和数字) 有用词的细微变化外, 是一致的。《欧盟教育培训学科》1999 版 (FoET 1999)系由《欧盟培训学科》1997 版(FoT 1997)发展并取代而来。《欧盟教育培训学 科》1999 版(FoET 1999)是一个 3 等级 (和 3 数字) 的层级分类法, 是《国际教育标准分类 法一教育培训学科》 ( ISECED-F) 目前修订的起点。

46. 《欧盟教育培训学科》1999 版(FoET 1999)在国际上用于不同的数据收集，例如:

- 注册人数和毕业生的行政数据

- 某些住户调查, 及

- 学生评估调查

47. 在开发《欧盟培训学科》1997 版(FoT 1997)和《欧盟教育培训学科》1999 版(FoET 1999)中, 广泛采用了《澳大利亚统计局资格证书分类法》1993 版（ABSCQ1993）。尽管在 2001 年 《澳大利亚教育标准分类法》 (ASCED) 取代了《澳大利亚统计局资格证书分类法》 (ABSCQ) , 但是《国际教育标准分类法一教育培训学科》（ISECED-F）分类法采用了《澳大 利亚统计局资格证书分类法》1993 版 (ABSCQ1993) 的某些概念和文本, 因为《欧盟教育培 训学科》1999 版(FoET 1999)是《国际教育标准分类法》学科修订的起点。

\section{与《国际职业标准分类法一08》 (ISCO-08) 的关系}

48. 《国际职业标准分类法 - 08 》 (ISCO-08) 是一个分类和汇总职业信息的系统, 这些职业信 息是通过人口普查和其它统计调查, 以及行政记录获得的。它的主要目的是为国际上报告和 比较工作和职业信息提供一个基础。

a. 工作定义为一个人为雇主或自雇完成或要完成的一组任务和职责。

b. 职业是主要任务和职责高度相似的一组工作。一个人通过与其过去、现在或将来的工作 的关系而与一个职业产生联系。

49. 《国际职业标准分类法-08》采用两个基本准则将职业分组: 技能水平和技能专业。

a. 技术定义为执行一个给定工作的任务和职责的能力。

b. 技术水平是将要完成的任务和职责的复杂性和范围的函数。

c. 技术专业是根据所要求知识领域, 所使用的工具和机器, 工作的材料和所产生的货物和 服务类型来考虑的。 
50. 《国际职业标准分类法-08》（ISCO-08）的技术专业的概念与《国际教育标准分类法》 （ISCED）的教育培训的学科有一些相似。但是，《国际职业标准分类法-08》（ISCO-08） 和《国际教育标准分类法》 (ISCED) 采用不同的准则对不同的统计单位进行分类。《国际 教育标准分类法一教育培训的学科》 (ISCED-F) 根据课目实质内容对教育课程和资格证书 进行分类, 而《国际职业标准分类法-08》（ISCO-08）根据完成该工作所要求的技能水平和 专业对工作进行分类。因此, 尽管存在明显的联系, 两个分类法的职业和学科组之间并不总 是直接相对应的。

\section{与《科学与技术学科 2007》 (FoS2007) 分类法的关系}

51. 《科学与技术学科 2007》对研究与试验开发 (R\&D) 进行分类, 是《经济合作与发展组织弗 拉斯卡蒂手册》 (Frascati Manual)的一部分。《科学与技术学科》(FoS)最近于 2007 年修订。 《科学与技术学科 2007 》修订版见电子附件网页 [http://www.oecd.org/dataoecd/36/44/38235147.pdf]。《科学与技术学科》是一个 2-等级层 级分类法, 含有 6 个主要学科:

1. 自然科学

2. 工程与技术

3. 医学与卫生科学

4. 农业科学

5. 社会科学

6. 人文

这 6 个主要学科被分成大约 40 个 2 级学科。

52. 2007 年修订《科学与技术学科》的主要原因是, 出现了如信息和通信技术、生物技术、纳米 技术以及出现了交叉学科科学。

53. 《国际职业标准分类法-08》 (ISCO-08) 和《科学与技术学科 2007》都用来识别新出现的学 科, 以纳入《国际教育标准分类法一教育培训的学科》（ISCED-F）中。

54. 为了避免不必要的区别, 《国际教育标准分类法一教育培训的学科》 (ISCED-F) 相关的部 分与《科学与技术学科》也做了比较。但是, 应意识到《科学与技术学科》与《国际教育标 准分类法一教育培训的学科》 (ISCED-F) 有不同的目的, 不能保证两个分类法之间一定有 直接的对应。 


\section{附件 1：《国际教育标准分类法一教育培训的学科》（ISCED-F）}

\begin{tabular}{|c|c|c|}
\hline 宽学科 & 窄学科 & 细学科 \\
\hline 00 通用课程和资格证书 & $\begin{array}{l}001 \text { 基础课程和资格证书 } \\
002 \text { 识字与算术 } \\
003 \text { 个人技能和发展 }\end{array}$ & $\begin{array}{l}0011 \text { 基础课程和资格证书 } \\
0021 \text { 识字与算术 } \\
0031 \text { 个人技能和发展 }\end{array}$ \\
\hline 01 教育 & 011 教育 & $\begin{array}{l}0111 \text { 教育科学 } \\
0112 \text { 学前教师培训 } \\
0113 \text { 无专业课目的教师培训 } \\
0114 \text { 有专业课目的教师培训 }\end{array}$ \\
\hline \multirow[t]{3}{*}{02 艺术与人文 } & 021 艺术 & $\begin{array}{l}0211 \text { 视听技术与传媒制作 } \\
0212 \text { 服装设计、室内设计与工业设计 } \\
0213 \text { 美术 } \\
0214 \text { 手工艺品 } \\
0215 \text { 音乐与表演艺术 }\end{array}$ \\
\hline & 022 人文 (不包括语言) & $\begin{array}{l}0221 \text { 宗教与神学 } \\
0222 \text { 历史与考古学 } \\
0223 \text { 哲学与伦理学 }\end{array}$ \\
\hline & 023 语言 & $\begin{array}{l}0231 \text { 语言学习 } \\
0232 \text { 文学与语言学 }\end{array}$ \\
\hline \multirow[t]{2}{*}{03 社会科学、新闻学与信息 } & 031 社会与行为科学 & $\begin{array}{l}0311 \text { 经济学 } \\
0312 \text { 政治科学与公民学 } \\
0313 \text { 心理学 } \\
0314 \text { 社会学与文化研究 }\end{array}$ \\
\hline & 032 新闻学与信息 & $\begin{array}{l}0321 \text { 新闻学与报道 } \\
0322 \text { 图书馆学、信息与档案研究 }\end{array}$ \\
\hline \multirow[t]{2}{*}{04 商业、行政与法律 } & 041 商业与行政 & $\begin{array}{l}0411 \text { 会计与税务 } \\
0412 \text { 金融、银行与保险 } \\
0413 \text { 管理与行政 } \\
0414 \text { 市场营销与广告 } \\
0415 \text { 秘书与办公室工作 } \\
0416 \text { 批发与零售 } \\
0417 \text { 工作技能 }\end{array}$ \\
\hline & 042 法律 & 0421 法律 \\
\hline
\end{tabular}




\begin{tabular}{|c|c|c|}
\hline 宽学科 & 窄学科 & 细学科 \\
\hline \multirow[t]{4}{*}{05 自然科学、数学与统计 } & 051 生物及相关科学 & $\begin{array}{l}0511 \text { 生物学 } \\
0512 \text { 生物化学 }\end{array}$ \\
\hline & 052 环境 & $\begin{array}{l}0521 \text { 环境科学 } \\
0522 \text { 自然环境与野生动植物 }\end{array}$ \\
\hline & 053 物理科学 & $\begin{array}{l}0531 \text { 化学 } \\
0532 \text { 地球科学 } \\
0533 \text { 物理 }\end{array}$ \\
\hline & 054 数学与统计学 & $\begin{array}{l}0541 \text { 数学 } \\
0542 \text { 统计学 }\end{array}$ \\
\hline 06 信息与通信技术 (ICTs) & 061 信息与通信技术 (ICTs) & $\begin{array}{l}0611 \text { 计算机应用 } \\
0612 \text { 数据库与网络设计和管理 } \\
0613 \text { 软件及应用开发和分析 }\end{array}$ \\
\hline \multirow[t]{3}{*}{07 工程、制造与建筑 } & 071 工程与工程行业 & $\begin{array}{l}0711 \text { 化学工程与工艺 } \\
0712 \text { 环境保护技术 } \\
0713 \text { 电力与能源 } \\
0714 \text { 电子与自动化 } \\
0715 \text { 机械与金属行业 } \\
0716 \text { 机动车辆、船舶与飞机 }\end{array}$ \\
\hline & 072 制造与加工 & $\begin{array}{l}0721 \text { 食品加工 } \\
0722 \text { 材料 (玻璃、纸张、塑料与木材) } \\
0723 \text { 纺织品 (服装、鞋类与皮革) } \\
0724 \text { 采矿与冶炼 }\end{array}$ \\
\hline & 073 建筑学与建筑工程 & $\begin{array}{l}0731 \text { 建筑学与城镇规划 } \\
0732 \text { 建筑与土木工程 }\end{array}$ \\
\hline
\end{tabular}




\begin{tabular}{|c|c|c|}
\hline 宽学科 & 窄学科 & 细学科 \\
\hline \multirow[t]{4}{*}{08 农业、林业、渔业与兽医学 } & 081 农业 & $\begin{array}{l}0811 \text { 作物与畜牧生产 } \\
0812 \text { 园艺学 }\end{array}$ \\
\hline & 082 林业 & 0821 林业 \\
\hline & 083 渔业 & 0831 渔业 \\
\hline & 084 兽医学 & 0841 兽医学 \\
\hline \multirow[t]{2}{*}{09 卫生与福利 } & 091 卫生 & $\begin{array}{l}0911 \text { 牙科 } \\
0912 \text { 医学 } \\
0913 \text { 护理与助产 } \\
0914 \text { 医疗诊断与治疗技术 } \\
0915 \text { 治疗与康复 } \\
0916 \text { 药学 } \\
0917 \text { 传统和补充医学及治疗 }\end{array}$ \\
\hline & 092 福利 & $\begin{array}{l}0921 \text { 老人和残疾成年人保健 } \\
0922 \text { 儿童保健与青少年服务 } \\
0923 \text { 社会工作与咨询 }\end{array}$ \\
\hline \multirow[t]{4}{*}{10 服务业 } & 101 个人服务 & $\begin{array}{l}1011 \text { 家政服务 } \\
1012 \text { 美发美容服务 } \\
1013 \text { 旅馆、餐厅与餐饮 } \\
1014 \text { 体育 } \\
1015 \text { 旅行、旅游与休闲 }\end{array}$ \\
\hline & 102 卫生与职业卫生服务 & $\begin{array}{l}1021 \text { 社区卫生 } \\
1022 \text { 职业卫生与安全 }\end{array}$ \\
\hline & 103 安全服务 & $\begin{array}{l}1031 \text { 军事与国防 } \\
1032 \text { 人员与财产保护 }\end{array}$ \\
\hline & 104 运输服务 & 1041 运输服务 \\
\hline \multicolumn{3}{|c|}{ 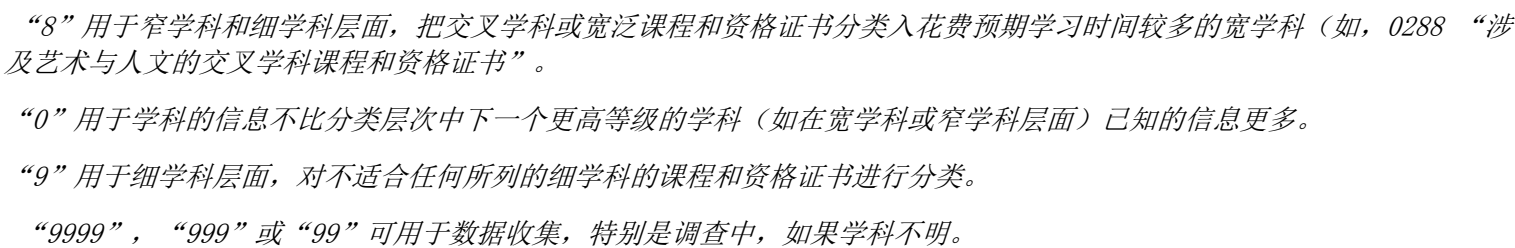 } \\
\hline
\end{tabular}


《国际教育标准分类法》是《联合国经济与社会分类法国际系列》中的一员, 是国际认可以教 育等级和学科来组织安排教育课程和相关资格证书的参考分类。《国际教育标准分类法》最 早于20世纪70年代开发, 是一个收集、汇编和分析国家间可比较教育统计的国际认可框架。

拥有一部共同的国际分类法, 仅是向收集可比较数据迈出了第一步。第二步是保证该分类 法在各国家应用的一致性。《国际教育标准分类法》2011修订版, 主要着重于对课程的教 育等级 (ISCED-P) 的修改, 并首次引入一个以资格证书为基础的的受教育程度等级分类法

（ISCED-A）。2013年通过了《教育培训学科》修订版（ISCED-F）。该分类法主要旨在描述和 归类《国际教育标准分类法》2011版中所定义的中等、中等后和高等教育等级中的教育培训学 科。

联合国教科文组织统计研究所是《国际教育标准分类法》系列 (ISCED-P、ISCED-A 和 ISCED-F）的监管机构, 负责其开发、维护、更新和修订。本研究所在国际数据收集和分析方 面为有效和一致地使用《国际教育标准分类法》提供指导。

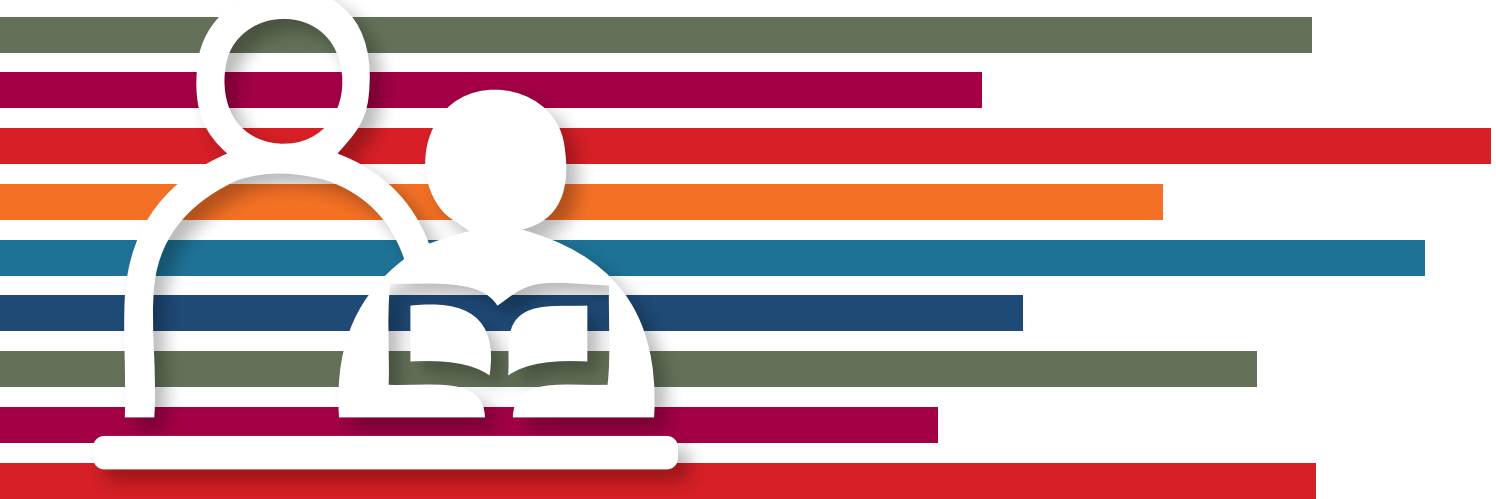

联合国教科文组织统计研究所是联合国教科文组织的统计机构, 是教 统计研究所育、科技、文化和信息方面国际统计资料的联合国保管者。 